\title{
Association between bone turnover markers and adipocytokines among obese patients with type 2 diabetes
}

\begin{abstract}
Background: Type 2 diabetes (T2DM) is a chronic and progressive disease that is strongly associated with increased the risk of fracture due to altered bone microarchitecture and/or poor quality as key factors.

Objective: The present study aimed to detect the association between bone turnover markers and adipocytokines among obese patients T2DM.

Material and Methods: One hundred obese Saudi patients with T2DM (57 men and 43 women). Their age was $45.38 \pm 5.12$ year, and a control group included one hundred healthy volunteers, who was gender and age matched.

Results: Obese T2DM patients had significantly lower values of adiponectin, Bone Alkaline Phosphatase (BAP) and Bone Cross-linked N-telopeptides of Type Collagen (NTX) in addition to significantly higher values of leptin, resistin, visfatin levels in comparison to controls. Also, serum level of adiponectin showed an inverse relationship with BAP and NTX. While Serum levels leptin, resistin and visfatin showed an inverse relationship with BAP and NTX.

Conclusion: Within the limit of this study, serum level of adiponectin showed a direct relationship with bone turnover markers. While Serum levels leptin, resistin and visfatin showed an inverse relationship with bone turnover markers in obese patients with type 2 diabetes mellitus.
\end{abstract}

Keywords: adipocytokines, type 2 diabetes, obesity, bone turnover
Volume 7 Issue 2 - 2017

\author{
Mohammed H Saiem Al Dahr, Essam H jiffri \\ Department of Medical Laboratory Technology, King Abdulaziz \\ University, Saudi Arabia
}

\begin{abstract}
Correspondence: Mohammed H Saiem Al-Dahr, Department of Medical Laboratory Technology, Faculty of Applied Medical Sciences, King Abdulaziz University, P.O. Box 80324, Jeddah, 21589, Saudi Arabia, Tel 9665056085I0.

Emailmdahr@kau.edu.sa
\end{abstract}

Received: May II, 2017| Published: July 19, 2017

\section{Introduction}

Type 2 diabetes mellitus (T2DM) now affects at least 285 million people worldwide, and this number will raise to 438 million by the year 2030. ${ }^{1}$ Type 1 and type 2 diabetes mellitus are both associated to bone damage. ${ }^{2,3}$ There is clear evidence that patients with type 2 diabetes mellitus (T2DM) have increased fracture risk, despite having high bone mineral density (BMD) and body mass index (BMI). Thus, poor bone quality has been implicated as a mechanism contributing to diabetic skeletal fragility. ${ }^{4}$

Bone turnover biomarkers (BTMs) reflect bone formation and resorption, and therefore inform the status of bone remodeling, which is a mechanism underlying osteoporosis. ${ }^{5}$ In diabetic patients, bone remodeling appears to be impaired as both markers of bone formation and markers of bone resorption are decreased when compared to healthy subjects. ${ }^{6-9}$ Individuals with type 2 diabetes were reported to have higher BMD despite elevated risk of fractures. ${ }^{10,11}$ Thus, BTM can potentially be a more sensitive surrogate marker than BMD in assessing fracture risk among patients with diabetes, due to a possible linkage between BTMs and glucose metabolism. ${ }^{12,13}$

Bone turnover biomarkers (BTMs) include both bone formation and resorption markers. Bone formation biomarkers are synthesized by osteoblasts and therefore reflect specific osteoblastic functions, and these include bone alkaline phosphatase (ALP),${ }^{14}$ osteocalcin (OC),${ }^{15}$ and procollagen type I N propeptide (PINP). These bone formation markers have been proposed as possible predictors for osteoporosis ${ }^{16,19}$ and hip fracture risk..$^{20,21}$ Bone resorption markers are degradation products of type I collagen ${ }^{22}$ and include C-terminal crosslinking telopeptide of type I collagen (CTX-I) and N-terminal crosslinking telopeptide of type I collagen (NTX-I). ${ }^{22}$ Increased CTX-I and NTX-I levels have also been reported to be inversely correlated with BMD among women ${ }^{16,18}$ and to be significant predictors for non-spine fractures independent of BMD in several longitudinal studies. ${ }^{16,23,24}$

Body fat and bone mineral density (BMD) are directly related..$^{25}$ Although mechanical loading may contribute to this relationship, other factors are also involved. ${ }^{26}$ One such factor is adiponectin which is a recently discovered adipocytokine that is specifically and highly expressed in human adipose tissue $\mathrm{e}^{27}$ as adiponectin acts directly on bone to induce human osteoblast proliferation and differentiation, and to increase osteoclast formation. ${ }^{28}$ Richards et al. ${ }^{29}$ showed that adiponectin exert an independent negative effect on BMD. ${ }^{29}$ Some data also showed that there were no independent relationship between adiponectin and BMD. ${ }^{30}$ Leptin is an adipocytokines released by adipose tissue, and is strongly correlated with fat mass. ${ }^{31}$ The reduction in femoral length and weight has been reported in obese leptin receptor-deficient rats, and the peripheral infusion of leptin to ovariectomized rats prevented their further loss of bone. ${ }^{32}$ By contrast, in leptin-deficient mice and leptin receptor-deficient mice, increases in bone formation and bone mass have been reported. ${ }^{33}$ Similarly, human studies on the role of leptin in bone mass in women have shown contradictory results. ${ }^{30}$ The other adipocytokine, Resistin is an adipocytokine that was discovered recently and seems to play a role in glucose homeostasis, insulin resistance and inflammation. ${ }^{34}$ Oh et $a l .^{35}$ showed that serum resistin level showed a significant negative correlation with lumbar spine BMD in middle-aged men, but the variance was small. ${ }^{35}$ Also, Visfatin is a novel adipocytokine 
that is highly expressed in visceral fat, and binds to and activates the insulin receptor and exerts insulin-mimetic effects which have a role in regulation of glucose uptake, proliferation and type I collagen production in human osteoblasts. ${ }^{36}$ The purpose of this study was to determine the strength of the association between bone turnover markers and adipocytokines among obese patients with type 2 diabetes.

\section{Materials and methods}

\section{Subjects}

One hundred Saudi obese T2DM patients ( 57 men and 43 women) with body mass index (BMI) ranged from 30 to $36 \mathrm{Kg} / \mathrm{m}^{2}$, were selected from the out-patient diabetic clinic of the King Abdalziz Teaching Hospital. They were checked for fasting/random glucose levels. Only participants have fasting blood sugar levels more than 5.6 $\mathrm{mmol} / \mathrm{l}$ or random blood sugar level more than $7.8 \mathrm{mmol} / \mathrm{l}$ (impaired blood sugar) were included in this study and were further checked for type 2 diabetes mellitus as per recent American Diabetes Association criteria i.e. fasting blood sugar $\geq 7.0 \mathrm{mmol} / 1$ or post-prandial blood sugar $\geq 11.1 \mathrm{mmol} / 1$ [2-h plasma glucose $11.1 \mathrm{mmol} / 1$ during an oral glucose tolerance test] and glycosylated hemoglobin ( $\mathrm{HbAlc} \%$ ) $>6.5 \% .{ }^{37}$ Exclusion criteria included smokers, congestive heart failure, pregnant female patients, hypertension, chronic liver disease, coronary artery disease, angiopathy, myocardial infarction, cerebral infarction and infectious disease. Subjects were also excluded from the study if they had conditions affecting bone metabolism, including diseases of the kidney, liver, parathyroid, or thyroid, diabetes mellitus, hyperprolactinemia, oophorectomy, rheumatoid arthritis, ankylosing spondylitis, malabsorption syndromes, malignant tumors, hematologic diseases, previous pathological fractures. If the subjects had received treatment with glucocorticoids, estrogens, thyroid hormone, parathyroid hormone, fluoride, bisphosphonate, calcitonin, thiazide diuretics, barbiturates, anti-seizure medication, they were also excluded.

A detail clinical history and physical examinations were conducted which included the age, sex, symptoms suggestive of diabetes and family history of diabetes. Physical examinations included anthropometric measurements such as height, weight, body mass index (BMI) and waist circumference. Also, One hundred apparently healthy, medically free, and treatment naive individuals were recruited to serve as non-diabetic control. Informed written consent was obtained from each included subjects.

\section{Laboratory analysis}

For the biochemical estimations, venous blood samples were collected between 7:00 A.M. and 9:00 A.M. after fasting overnight and the samples were allowed to clot. Thereafter, the samples were centrifuged and divided into aliquots and stored at $-70{ }^{\circ} \mathrm{C}$ until assayed.

Serum adiponectin, leptin, resistin, visfatin measurement: The levels of adiponectin in human serum were determined using adiponectin ELISA (Phoenix Pharmaceuticals, Inc., Belmont, CA). Serum leptin, resistin, and visfatin levels were detected using ELISA (Phoenix Pharmaceuticals). The intra- and inter-assay CVs were 5.0 and $6.0 \%$ for adiponectin, 6.0 and $7.1 \%$ for leptin, 6.1 and $7.3 \%$ for resistin, and 5.6 and $7.0 \%$ for visfatin.

Bone turnover biochemical markers measurement: The serum concentration of bone alkaline phosphatase (BAP) as the markers of bone formation were measured with ELISA kits (BAP from Metra ${ }^{\mathrm{TM}}$
BAP EIA kit, Quidel Corp., San Diego, CA). As a marker of bone resorption, serum cross-linked N-telopeptides of type I collagen (NTX) were measured using an ELISA kit (Osteomark, Ostex, Inc., Seattle,WA). The intra- and inter-assay CVs were 5.1 and $7.0 \%$ for BAP, 5.3 and $7.9 \%$ for NTX, respectively. ${ }^{38}$

\section{Statistical analysis}

Independent t-test was used to compare mean differences between both groups. Statistical analysis of data was performed using SPSS (Chicago, IL, USA) version 17. The degree of correlation between bone turnover markers and adipocytokines among obese T2DM patients was detected by Pearson's product moment correlation coefficients (r).

\section{Results}

One hundred obese Saudi T2DM patients were enrolled including 57 men and 43 women, had a mean age of $45.38 \pm 5.12$ year and one hundred healthy subjects, had a mean age of $43.72 \pm 6.31$ years, there was no significant differences in body mass index between both groups. However, T2DM patients were more insulin resistant as indicated by higher values of insulin and HOMA-IR, and lower values of the quantitative insulin-sensitivity check index )QUICKI ( . Also, T2DM patients showed significantly higher glucose, insulin, Homeostasis Model Assessment-Insulin Resistance (HOMA-IR) index (Table 1).

Table I Baseline characteristics of type 2 diabetic patients and control subjects

\begin{tabular}{llll}
\hline & \multicolumn{2}{l}{ Mean \pm SD } & Significance \\
\cline { 2 - 3 } & Diabetic Group & Control Group & \\
\hline Age, year & $45.38 \pm 5.12$ & $43.72 \pm 6.31$ & $\mathrm{P}>0.05$ \\
Gender, M/F & $57 / 43$ & $55 / 44$ & $\mathrm{P}>0.05$ \\
$\mathrm{BMI}, \mathrm{kg} / \mathrm{m} 2$ & $33.62 \pm 3.14$ & $34.85 \pm 3.29$ & $\mathrm{P}>0.05$ \\
$\mathrm{FBS}, \mathrm{mg} / \mathrm{dl}$ & $184.58 \pm 10.17^{*}$ & $90.26 \pm 5.35$ & $\mathrm{P}<0.05$ \\
$\mathrm{PPS}, \mathrm{mg} / \mathrm{dl}$ & $241.24 \pm 15.32^{*}$ & $119.76 \pm 9.66$ & $\mathrm{P}<0.05$ \\
Insulin, $\mathrm{mU} / \mathrm{l}$ & $15.41 \pm 3.1$ * $^{*}$ & $8.57 \pm 2.48$ & $\mathrm{P}<0.05$ \\
QUICKI & $0.123 \pm 0.016^{*}$ & $0.169 \pm 0.021$ & $\mathrm{P}<0.05$ \\
HOMA-IR & $5.75 \pm 1.58^{*}$ & $2.63 \pm 1.14$ & $\mathrm{P}<0.05$ \\
HBAIc,\% & $9.13 \pm 2.74^{*}$ & $6.25 \pm 1.15$ & $\mathrm{P}<0.05$
\end{tabular}

BMI: Body Mass Index; FBS: Fasting Blood Sugar; PPS: Postprandial Blood Sugar; HOMA-IR: Homeostasis Model Assessment-Insulin Resistance (HOMA-IR) index; QUICKI: The quantitative insulin-sensitivity check index; HBA1c: Glycosylated Hemoglobin; $(*)$ indicates a significant difference between the two groups, $\mathrm{P}<0.05$.

Table 2 summarizes the comparison between T2DM patients and matched controls. T2DM patients were more leptin, resistin, visfatin, BAP and NTX in addition to significantly lower values of adiponectin levels in comparison to controls (Table 2). Table 3 summarizes the relationship between parameters of bone turnover markers and adipocytokines among obese T2DM patients. Serum levels of level of adiponectin showed a direct relationship with BAP and NTX. While Serum levels leptin, resistin and visfatin showed an inverse relationship with BAP and NTX (Table 3). 
Table 2 Mean value and significance of biochemical parameters of type 2 diabetic patients and control subjects

\begin{tabular}{lllll}
\hline & \multicolumn{2}{l}{ Mean \pm SD } & \multirow{2}{*}{ T-Value } & Significance \\
\cline { 2 - 3 } & Diabetic Group & Control Group & & \\
\hline Adiponectin, $\mu \mathrm{g} / \mathrm{ml}$ & $6.73 \pm 2.34$ & $13.46 \pm 4.91$ & 7.64 & $\mathrm{P}<0.05$ \\
Leptin, $\mathrm{ng} / \mathrm{ml}$ & $24.25 \pm 8.7 \mathrm{I}$ & $12.18 \pm 4.26$ & 6.83 & $\mathrm{P}<0.05$ \\
Resistin, $\mathrm{ng} / \mathrm{ml}$ & $7.88 \pm 1.94$ & $5.22 \pm 1.32$ & 6.14 & $\mathrm{P}<0.05$ \\
Visfatin, $\mathrm{ng} / \mathrm{mL}$ & $37.21 \pm 10.16$ & $22.63 \pm 9.68$ & 7.55 & $\mathrm{P}<0.05$ \\
BAP, U/l & $18.13 \pm 6.81$ & $28.74 \pm 11.43$ & 7.18 & $\mathrm{P}<0.05$ \\
NTX, nmol BCE & $12.95 \pm 5.23$ & $16.33 \pm 7.15$ & 6.22 & $\mathrm{P}<0.05$ \\
\hline
\end{tabular}

Table 3 Pearson's correlation coefficients test value of the studied variables in the type 2 diabetic group

\begin{tabular}{lll}
\hline & BAP (U/I) & NTX (nmol BCE) \\
\hline Adiponectin, $\mu g / \mathrm{ml}$ & $0.587^{*}$ & $0.57 \mathrm{I}^{*}$ \\
Leptin, $\mathrm{ng} / \mathrm{ml}$ & $0.612^{*}$ & $0.628^{*}$ \\
Resistin, $\mathrm{ng} / \mathrm{ml}$ & $0.576^{*}$ & $0.613^{*}$ \\
Visfatin, $\mathrm{ng} / \mathrm{mL}$ & $0.625^{*}$ & $0.615^{*}$
\end{tabular}

BAP, bone alkaline phosphatase; NTX, N-telopeptides of Type I Collagen, Spearman's correlation was used $*: \mathrm{P}<0.05$

BAP: Bone Alkaline Phosphatase; NTX: Bone Cross-linked N-telopeptides of Type Collagen; $(*)$ indicates a significant difference between the two groups, $\mathrm{P}<0.05$.

\section{Discussion}

Recently, there is a growing interest in the association between diabetes and alterations in bone metabolism. On the other hand, the effects of type 2 diabetes on bone are less clear-cut, whereas bone mineral density has been reported to be either unchanged or modestly increased, incidence of low-stress fractures is almost doubled, pointing to a decrease in the bone quality of these patients..$^{39}$ Thus, we investigated the relationships between serum levels of adipocytokines, including adiponectin, leptin, resistin \& visfatin and bone turnover biochemical markers (Serum BAP as a bone formation marker, and serum NTX as a bone resorption marker were assayed) among obese type 2 diabetic patients.

Our main result finding of the present study was that adiponectin significant was positively correlated with BAP and NTX. This finding supports the hypothesis that adiponectin may play a significant role in regulating bone mass among obese type 2 diabetic patients. Adiponectin was negatively correlated with fat mass, while the leptin showed a positive correlation. The correlation between leptin and fat mass remained significant. Furthermore, the finding that adiponectin was positively correlated with NTX and BAP. Thus, adiponectin may exert a negative effect on bone mass by promoting excessive bone resorption associated with bone loss among obese type 2 diabetic patients. Several experiments have shown that adiponectin could stimulate bone formation ${ }^{40,41}$ and regulate bone turnover. ${ }^{42}$ Several studies also documented a significant positive relationship between serum adiponectin and bone markers. ${ }^{43,44}$ However, Peng et al. ${ }^{45}$ investigated the relationship between serum adipocytokines levels and both bone marrow density and bone turnover biochemical markers in 232 Chinese men their age ranged between 20-80 years, they concluded that there were significant positive correlations between adiponectin and NTX, BAP. ${ }^{45}$ Also, Wu et al. ${ }^{46}$ investigated the relationships between serum adiponectin concentration and bone mineral density, and bone biochemical markers in 265 premenopausal and 336 postmenopausal Chinese women and proved that there were significant positive correlations between adiponectin and NTX, BAP in postmenopausal women. However, in premenopausal women, adiponectin was not related to NTX and BAP. ${ }^{46}$ Thus, adiponectin appears to mediate bone formation and bone remodeling, and serum hypoadiponectinemia may cause low turnover and lead to bone fragility in patients with type 2 diabetes. ${ }^{47}$

The exact mechanism by which adiponectin is strongly associated with bone formation and bone remodeling can be explained by several characteristics of adiponectin provide plausible avenues for modulation of bone metabolism. Adiponectin bears marked structural similarity to TNF- $\alpha$ family members, examples including RANK-L and osteoprotegerin, two proteins involved in regulation of osteoclastogenesis. Adiponectin activates. ${ }^{48}$ as well as inhibits ${ }^{49}$ $\mathrm{NF}-\mathrm{\kappa B}$, a ubiquitous transcription factor which is critical for osteoclastogenesis, providing a mechanism by which adiponectin may affect bone. Recombinant adiponectin prevents adipogenesis in bone marrow derived pre-adipocytes, suggesting that it can influence the marrow environment. ${ }^{50}$ Adiponectin is structurally similar to CORS26 (collagenous repeat-containing sequence of $26-\mathrm{kDa}$ protein), a novel protein discovered in a mouse embryonic fibroblast cell line, which is likely to be involved in skeletogenesis.$^{51}$ Another similar protein is Type X collagen, and mutations in the COL10A1 gene are known to cause metaphyseal chondrodysplasia (type Schmid). ${ }^{52,53}$ Thus, while the precise effects of adiponectin on the skeleton are not known, there are several potential mechanisms.

In this study, we observed that baseline serum leptin, resistin and visfatin levels inversely correlated with changes in NTX and BAP. However, previous studies stated that the relationship between serum leptin level and bone turnover markers was still controversial. ${ }^{54-57}$ Tamura et al. ${ }^{54}$ investigated the associations of serum level of leptin or adiponectin with bone mineral density, serum osteocalcin, and urinary N-terminal telopeptide of type I collagen (NTX) in 40 Japanese patients with type 2 diabetes mellitus and revealed that there were significant positive correlations between serum leptin or adiponectin level and $\mathrm{z}$ score at the distal radius and a significant negative correlation between serum leptin and urinary NTX, a marker of bone resorption. ${ }^{54} \mathrm{Wu}$ et al. ${ }^{55}$ proved that there were no significant correlations between leptin concentrations and NTX and BAP in premenopausal and postmenopausal women. ${ }^{55}$ Peng et al. ${ }^{56}$ concluded that there were significant positive correlations between adiponectin and NTX and BAP. There were no significant correlations between leptin, resistin, visfatin levels and NTX and BAP among Chinese men. ${ }^{56}$ Moreover, Fisher and coworkers determined the relationship 
of serum resistin concentrations to biochemical parameters of bone turnover and mineral metabolism among 256 elderly patients with hip fracture and founded a positive association between serum resistin, parathyroid and calcium levels in patients with cervical hip fracture. ${ }^{57}$ Moreover, the major limitations of the present study is only Saudi obese T2DM patients enrolled in the study, so the value of this study only related only to Saudi subjects, also small sample size in the two groups may limit the possibility of generalization of the findings in the present study. Finally, within the limit of this study, serum level of adiponectin showed a direct relationship with bone turnover markers. While serum levels leptin, resistin and visfatin showed an inverse relationship with bone turnover markers in obese patients with type 2 diabetes mellitus.

\section{Acknowledgments}

None.

\section{Conflicts of interest}

The authors declare there are no conflicts of interest related to the article.

\section{Funding}

None.

\section{References}

1. Whiting DR, Guariguata L, Weil C, et al. IDF diabetes atlas: global estimates of the prevalence of diabetes for 2011 and 2030. Diabetes Res Clin Pract. 2011;94(3):311-321.

2. Carnevale V, Romagnoli E, D'Erasmo E. Skeletal involvement in patients with diabetes mellitus. Diabetes Metab Res Rev. 2004;20(3):196-204.

3. Merlotti D, Gennari L, Dotta F, et al. Mechanisms of impaired bone strength in type 1 and 2 diabetes. Nutr Metab Cardiovasc Dis. 2010;20(9):683-690.

4. Karim L, Bouxsein ML. Effect of type 2 diabetes-related non-enzymatic glycation on bone biomechanical properties. Bone. 2016;82:21-27.

5. Devogelaer JP, Boutsen Y, Gruson D, et al. Is there a place for bone turnover markers in the assessment of osteoporosis and its treatment? Rheum Dis Clin N Am. 2011;37(3):365-386.

6. Oz SG, Guven GS, Kilicarslan A, et al. Evaluation of bonemetabolism and bone mass in patients with type-2 diabetes mellitus. $J$ NatlMed Assoc. 2006;98(10):1598-1604.

7. Gaudio A, Privitera F, Battaglia K, et al. Sclerostin levels associated with inhibition of the Wnt/beta-catenin signaling and reduced bone turnoverin type 2 diabetes mellitus. J Clin Endocrinol Metab. 2012;97(10):37443750 .

8. Ardawi MS, Akhbar DH, Alshaikh A, et al. Increased serum sclerostin and decreased serum IGF-1 are associated with vertebral fractures among postmenopausal women with type-2 diabetes. Bone. 2013;56(2):355362.

9. Gennari L, Merlotti D, Valenti R, et al. Circulating sclerostin levels andbone turnover in type 1 and type 2 diabetes. J Clin Endocrinol Metab. 2012;97(5):1737-1744.

10. Jackuliak P, Payer J. Osteoporosis, fractures, and diabetes. Int $J$ Endocrinol. 2014;2014:820615

11. Starup-Linde J, Eriksen SA, Lykkeboe S, et al. Biochemical markers of bone turnover in diabetes patients-a meta-analysis, and a methodological study on the effects of glucose on bonemarkers. Osteoporos. 2014;25(6):1697-1708.
12. Clemens TL, Karsenty G. The osteoblast: an insulin target cell controlling glucose homeostasis. J Bone Miner Res. 2011;26(4): 677-680.

13. Kindblom JM, Ohlsson C, Ljunggren $\mathrm{O}$, et al. Plasma osteocalcin is inversely related to fat mass and plasma glucose in elderly Swedish men. J Bone Miner Res. 2009;24(5):785-791.

14. Delmas PD, Eastell R, Garnero P, et al. The use of biochemical markers of bone turnover in osteoporosis Committee of Scientific Advisors of the International Osteoporosis Foundation. Osteoporos Int. 2000;11(Suppl 6: S2-S17),

15. AJ Lee, S Hodges, R Eastell. Measurement of osteocalcin. Ann Clin Biochem. 2000;37(Pt 4):432-446.

16. Garnero P, Sornay-Rendu E, Chapuy MC, et al. Increased bone turnover in late postmenopausal women is a major determinant of osteoporosis, $J$ Bone Miner Res. 1996;11(3):337-349.

17. O Lofman, P Magnusson, G Toss, et al. Common biochemical markers of bone turnover predict future bone loss: a 5-year follow-up study. Clin Chim Acta. 2005;356(1-2):670-675.

18. YZ Pi, XP Wu, SP Liu, et al. Age-related changes in bone biochemical markers and their relationship with bone mineral density in normal Chinese women. J Bone Miner Metab. 2006;24(5):380-385.

19. N Yoshimura, S Muraki, H Oka, et al. Biochemical markers of bone turnover as predictors of osteoporosis and osteoporotic fractures in men and women: 10-year follow-up of the Taiji cohort. Mod Rheumatol. 2011;21(6):608-620.

20. P Szulc, MC Chapuy, PJ Meunier, et al. Serum undercarboxylated osteocalcin is a marker of the risk of hip fracture in elderly women. Bone. 1993;18(5):487-488.

21. P Vergnaud, P Garnero, PJ Meunier, et al. Undercarboxylated osteocalcin measured with a specific immunoassay predicts hip fracture in elderly women: the EPIDOS Study, J Clin Endocrinol Metab. 1997;82(3):719724

22. NB Watts. Clinical utility of biochemical markers of bone remodeling. Clin Chem. 1999;45(8 Pt 2):1359-1368.

23. RD Chapurlat, P Garnero, G Breart, et al. Serumtype I collagen breakdown product (serum CTX) predicts hip fracture risk in elderly women: the EPIDOS study. Bone. 2000;27(2):283-286.

24. PD Ross, BC Kress, RE Parson, et al. Serum bone alkaline phosphatase and calcaneus bone density predict fractures: a prospective study. Osteoporos Int. 2000;11(1):76-82.

25. Khosla S, Atkinson EJ, Riggs BL, et al. Relationship between body composition and bone mass in women. $J$ Bone Miner Res. 1996;11(6):857-863.

26. Hla MM, Davis JW, Ross PD, et al. A multicenter study of the influence of fat and lean mass on bone mineral content: evidence for differences in their relative influence at major fracture sites. Early Postmenopausal Intervention Cohort (EPIC) Study Group. Am J Clin Nutr. 1996;64(3):354-360.

27. Luo XH, Guo LJ, Yuan LQ, et al. Adiponectin stimulates human osteoblasts proliferation and differentiation via the MAPK signaling pathway. Exp Cell Res. 2005;309(1):99-109.

28. Luo XH, Guo LJ, Xie H, et al. Adiponectin stimulates RANKL and inhibits OPG expression in human osteoblasts via the MAPK signaling pathway. J Bone Miner Res. 2006;21(10):1648-1656.

29. Richards JB, Valdes AM, Burling K, et al. Serum adiponectin and bone mineral density in women. J Clin Endocrinol Metab. 2007;92(4):15171523.

30. Kontogianni MD, Dafni UG, Routsias JG, et al. Blood leptin and adiponectin as possible mediators of the relation between fat mass and BMD in perimenopausal women. J Bone Miner Res. 2004;19(4):546551 . 
31. Thomas T, Burguera B, Melton LJ 3rd, et al. Relationship of serum leptin levels with body composition and sex steroid and insulin levels in men and women. Metabolism. 2000;49(10):1278-1284.

32. Burguera B, Hofbauer LC, Thomas T, et al. Leptin reduces ovariectomyinduced bone loss. Endocrinology. 2000;142:3546-3453.

33. Ducy P, Amling M, Takeda S, et al. Leptin inhibits bone formation through a hypothalamic relay: a central control of bone mass. Cell. 2000;100(2):197-207.

34. Steppan CM, Bailey ST, Bhat S, et al. The hormone resistin links obesity to diabetes. Nature. 2001;409(6818):307-312.

35. Oh KW, Lee WY, Rhee EJ, et al. The relationship between serum resistin, leptin, adiponectin, ghrelin levels and bone mineral density in middle-aged men. Clin Endocrinol. 2005;63(2):131-138.

36. Xie H, Tang SY, Luo XH, et al. Insulin-like effects of visfatin on human osteoblasts. Calcif Tissue Int. 2007;80(3):201-210.

37. American Diabetes Association. Diagnosis and classification of diabetes mellitus. Diabetes Care. 2010;33(Suppl 1):S62-S69.

38. Luo XH, Guo LJ, Shan PF, et al. Relationship of circulatingMMP-2, MMP-1, and TIMP-1 levels with bone biochemical markers and bone mineral density in postmenopausal Chinese women. Osteoporos Int 2006;17(4):521-526.

39. Janghorbani M, Feskanich D, Willett WC, et al. Prospective study of diabetes and risk of hip fracture. The Nurses' Health Study Diabetes Care. 2006;29(7):1573-1578.

40. Kanazawa I, Yamaguchi T, Yano S, et al. Adiponectin and AMP kinase activator stimulate proliferation, differentiation, and mineralization of osteoblastic MC3T3-E1 cells. BMC Cell Biol. 2007;8:51

41. Oshima K, Nampei A, Matsuda M, et al. Adiponectin increases bone mass by suppressing osteoclast and activating osteoblast. Biochem Biophys Res Commun. 2005;331(2):520-526.

42. Luo XH, Guo LJ, Xie $\mathrm{H}$, et al. Adiponectin stimulates RANKL and inhibits OPG expression in human osteoblasts through the MAPKsignaling pathway. J Bone Miner Res. 2006;21(10):1648-1656.

43. Richards JB, Valdes AM, Burling K, et al. Serum adiponectin and bone mineral density in women. J Clin Endocrinol Metab . 2007;92(4):15171523 .

44. Gregorio F, Cristallini S, Santeusanio F, et al. Osteopenia associated with non-insulin-dependent diabetes mellitus: what are the causes? Diabetes Res Clin Pract. 1994;23(1):43-54.

45. Peng XD, Xie H, Zhao Q, et al. Relationships between serum adiponectin, leptin, resistin, visfatin levels and bone mineral density, and bone biochemical markers in Chinese men. Clin Chim Acta. 2008;387(12):31-35.
46. Wu N, Wang QP, Li H, et al. Relationships between serum adiponectin, leptin concentrations and bone mineral density, and bone biochemical markers in Chinese women. Clin Chim Acta. 2010;411(9-10):771-775.

47. Kanazawa I, Yamaguchi T, Yamamoto M, et al. Combination of obesity with hyperglycemia is a risk factor for the presence of vertebral fractures in type 2 diabetic men. Calcif Tissue Int. 2008;83(5):324-331.

48. Tsao TS, Murrey HE, Hug C, et al. Oligomerization state-dependent activation of NF-kappa B signaling pathway by adipocyte complementrelated protein of $30 \mathrm{kDa}$ (Acrp30). J Biol Chem. 2002;277(33):2935929362.

49. Ouchi N, Kihara S, Arita Y, et al. Adiponectin, an adipocyte-derived plasma protein, inhibits endothelial NF-kappaB signaling through a cAMP-dependent pathway. Circulation. 2000;102(11):1296-1301.

50. Yokota T, Meka CS, Medina KL, et al. Paracrine regulation of fat cell formation in bone marrow cultures via adiponectin and prostaglandins. J Clin Invest. 2002;109(10):1303-1310.

51. Maeda N, Takahashi M, Funahashi T, et al. PPARgamma ligands increase expression and plasma concentrations of adiponectin, an adipose-derived protein. Diabetes. 2001;50(9):2094-2099.

52. Warman ML, Abbott M, Apte SS, et al. A type X collagen mutation causes Schmid metaphyseal chondrodysplasia. Nat Genet. 1993;5(1):79-82.

53. Wallis GA, Rash B, Sykes B, et al. Mutations within the gene encoding the alpha $1(\mathrm{X})$ chain of type $\mathrm{X}$ collagen (COL10A1) cause metaphyseal chondrodysplasia type Schmid but not several other forms of metaphyseal chondrodysplasia. J Med Genet. 1996;33:450-457.

54. Tamura T, Yoneda M, Yamane K, et al. Serum leptin and adiponectin are positively associated with bone mineral density at the distal radius in patients with type 2 diabetes mellitus Metabolism. Clinical and Experimental. 2007;56(5):623-628.

55. Wu N, Wang QP, Li H, et al. Relationships between serum adiponectin, leptin concentrations and bone mineral density, and bone biochemical markers in Chinese women. Clin Chim Acta. 2010;411(9-10):771-775.

56. Peng XD, Xie H, Zhao Q, et al. Relationships between serum adiponectin, leptin, resistin, visfatin levels and bone mineral density, and bone biochemical markers in Chinese men. Clin Chim Acta. 2008;387(12):31-35.

57. Fisher A, Southcott E, Li E, et al. Serum resistin in older patients with hip fracture: Relationship with comorbidity and biochemical determinants of bone metabolism. Cytokine. 2011;56(2):157-166. 